\title{
The Status Quo and Countermeasures of Community Security and Stabilization in Higher Vocational Colleges under the Background of "Internet Plus"
}

\author{
Yunshan Liu \\ School of Marxism, Wuxi Vocational Institute of Commerce, Wuxi, Jiangsu Province, China
}

Keywords: "Internet Plus"; higher vocational colleges; safety and stability; research

\begin{abstract}
Under the background of "Internet Plus", there are problems in the status quo of community security and stability in higher vocational colleges and in the working process of campus safety and stability. In order to improve the safety and stability of higher vocational colleges, it is necessary to make efforts in the three aspects, the supervision mechanism of returning time inspection at night, hygiene inspection and high-power appliance inspection, the promptness of classroom feedback and the closeness of parental contact, so that the community safety and stability of higher vocational colleges can be strengthened and improved.
\end{abstract}

\section{Introduction}

Nowadays, "Internet Plus" is an important new trend in the development of social forms in the world. Its essence means making full use of the optimized combination and integration of Internet technologies in the allocation of social resources, integrating the latest achievements of the Internet in all areas of economic and social development and improving the society. The productivity and creativity of the company will thus form a new form of Internet economy development with wider range and more benefits. For more than a decade, many industries at home and abroad have deeply integrated the field of "Internet Plus". For example, "Internet Plus" entrepreneurial innovation, industrial integration, benefit-based services, modernization of governance systems, key technology research and development and infrastructure construction, etc.

\section{The Meaning and Characteristics of the Concept of "Internet Plus"}

The meaning of "Plus" in "Internet Plus" refers to cross-border integration, which is open, reformed and reshaped. In the Internet age, only those who dare to cross the border can have innovation. Only by daring to merge, will there develop. As far as the world today is concerned, to achieve the sustainable development of human economy and society, we must rely on innovation-driven development. One of the goals and achievements of the G20 Hangzhou Summit held in September last year was also innovation-driven. We should make full use of Internet thinking to achieve change and self-reform and always attach great importance to and grasp the innovation-driven.

An important feature of "Internet Plus" is to reshape. In the era of the Internet, the Community of Shared Future for Mankind has undergone major structural reshaping. The original structure of economy, society, geography, culture and information has been broken. And the original power, discourse power and rules have been changed. Therefore, the "Internet Plus" social governance mechanism emerges in an endless stream and continues to affect all walks of life. The security and stability of higher vocational colleges are also affected. 


\section{The Status of Safety and Stability in Higher Vocational Colleges under the Background of "Internet Plus"}

\subsection{The status quo of safety and stability in higher vocational colleges.}

The safety and stability of vocational colleges in the context of "Internet Plus" is mainly to test and guarantee the theoretical knowledge and the professional and technical learning of students in school, as well as the application of theoretical knowledge and professional technology in practice. The security and stability of higher vocational colleges under the "Internet Plus" background is to insist on understanding students, caring for students, respecting students, caring for students, striving to promote the overall development of students. At present, the sources of students in higher vocational colleges are the new generation of the Internet. They have access to a wide range of information. Under the "Internet Plus" background, it is more difficult than before to do a good job of the safety and stability of college students. In this specific context, it is necessary to really consider the overall status quo of the society and the particularities of students. At the same time, it is necessary to carry out a variety of related activities based on their new interests, enrich their lives and actively carry out various types of safety and stability activities, so that the students can not only increase their knowledge in all aspects, but also exercise their abilities and enhance their safety and stability awareness.

In the specific security and stability work under the "Internet Plus" background, higher vocational colleges should take the promotion of the students' all-round development as a starting point and a foothold. In practice, we should respect the students' individual differences and respect their creativity. That is, we should based on the students' basic rights and each of them should be objectively and scientifically evaluated and be treated fairly. In the context of "Internet Plus", the universities that are at the forefront of the times must also keep up with the pace of the times, strive to achieve innovations in safety and stability, give the students enough development space and fully mobilize their enthusiasm, initiative and creativity in innovation and entrepreneurship. We should also establish long-term effective safety and stability working mechanisms to promote the students' all-round development, so that they can better play their advantages, correct their shortcomings and achieve sustainable development.

\subsection{The supervision mechanisms for returning time at night, hygiene and high-power appliance inspection.}

Firstly, the supervision mechanism for returning time at night, hygiene and high-power electrical appliance inspection. The inspection of returning time at night, hygiene and high-power appliances in higher vocational colleges is the responsibility of the members of the Community Self-Management Committee. As a unit, each department attends the inspection with the dormitory administrators in the dormitory. The inspection of returning time at night begins at 21:30, the inspections are carried out by the dormitory administrator and the Community Self-Management Committee. They mainly check that how many students have not returned to the dormitory and where they go after 21:30. They should ensure the students' personal safety in school. The inspection of returning time at night is mainly supervised by the on-duty counselors, dormitory administrators and cadres of the self-management committee. The inspection of hygiene and high-power appliances begins on Wednesdays at 13:00 on Wednesdays. Three teams participate. Each team is sent by one member of the Ministry of Hygiene and one member of the Ministry of Safety and Supervision. The dormitory administrator takes one team to carry out the inspections. The Ministry of Hygiene is responsible for the inspection of hygiene. In the case of cleaning, the Ministry of Safety and Supervision is responsible for checking whether there are any illegally used high-power appliances in the students' dormitory. Inspections of hygiene and high-power appliances mainly include community-responsible teachers, dormitory administrators and self-management cadres.

Secondly, the existing problems. The supervision methods of the inspection of returning time at night are supervised by dormitory administrators and self-administration cadres. Students in the same 
class may have harboring or biased imaginations, which may lead to security risks in the inspection process. Students scoring in their own class in the hygiene inspection may have a higher score for students who are in the class or who are closer to themselves. The inspection and supervision mechanism for high-power electrical appliances may cause students who are in charge of inspections to notify the students who are close to them notice them before the inspection.

\subsection{The timeliness and problems of the teachers' feedback on class attendance.}

Firstly, the timeliness of the feedback on class attendance. Classrooms are places where teachers teach and educate people. Classrooms are also places where students grow up. In the current class, the students are required to attend compulsory and elective courses selected by the students themselves. In the current class, the attendance check has three modes, that is, the teachers' attendance check, the student attendance check in the card machine and the attendance check of the discipline inspection committee. Attendance can reflect the safety and stability of a class. The general safety of classes with high class attendance will not cause too many problems. On the contrary, a class with poor attendance and cannot see the students all day is prone to safety problems. The timely feedback of class attendance data is of great significance to the safety of the entire school.

Secondly, the existing problems. The data of class attendance is conducted from the three ways at the same time. There may be discrepancies in attendance data. The management does not know which data should be used. It takes certain amount of time to verify the data. The attendance check in the card machine is the card operation of the machine. Although some students do not come to class, those in the same bedroom may help them swipe card. The teachers may have too many classes so that they cannot remember every student's name and appearance. Some students may help others to come to the class. Class disciplinary committee attendance is the students' attendance check. When the students who have a better relationship with the discipline inspection committee, even if the student has not attended class, the committee members may not report it.

\subsection{The closeness and problems of the contact between parents and teachers.}

Firstly, the closeness of parental contact. Colleges are an open place. The students are grouped together in classes. Generally, four classmates in the class live in a dormitory. They have to participate in class activities as well as necessary extracurricular activities. They come into contact with classmates. It is not limited to classmates and classroom teachers in their own class. Some students may not be able to adapt to the new city and the new environment and they will communicate with their parents, their relatives and friends. The school teachers and the head teacher sometimes cannot always be with the students. Some students cannot understand the hidden circumstances. Especially in the context of "Internet Plus", the students' contact with the outside world becomes more and more closely while ignore their teachers and classmates in real life. The teachers and parents need to be in close contact with each other and communicate and feedback in a timely manner. The parents give feedback to the teachers on the students' psychological conditions while the teachers should immediately provide the parents with feedback on the students' performance in schools, so that the schools and the parents can establish close relationships and promote the safety and stability of the school.

Secondly, the existing problems. Under the "Internet Plus" background, the rapid development of the Internet has led the students to rely more and more on the Internet. There has been less and less contact with parents. Under the "Internet Plus" background, the students can solve problems on the Internet without their parents, including the students' lack of money because they can refinance online. The students rely on the Internet more than their parents. Under the "Internet Plus" background, the students' dependence on the Internet is getting higher and higher; the demand for classes is getting smaller; and the connections with teachers are getting less and less. 


\section{Countermeasures of the Safety and Stability in Higher Vocational Colleges under the Background of "Internet Plus"}

\subsection{The supervision mechanism of community management is expanded to promote the stable development of higher vocational colleges.}

Higher vocational education is an important part of China's higher education. The popularization of higher education has created good environment for the development of higher vocational colleges in China. However, due to the limitation of traditional community-managed work methods, the procedures for community management work are too complicated. For a long time, the majority of students cannot enjoy the results of relevant community management. This is imperfect in the ointment of traditional community management. The characteristics of emerging media can solve this problem. That is, it can make community management more cost-effective, more efficient and more sustainable to the students, so that all the students can jointly improve hygiene and safety growth.

Under the conditions of information society, the main target of the community management work in higher vocational colleges is the youth groups that have grown up with the Internet. This situation requires that we must establish a strategic vision and actively promote the informationization of community management work through the establishment of the related new media numbers for community management work which will make the coverage of work education of community management wider and make the depth of influence stronger. By carrying out a series of activities on the new media, the Communist Party's influence can be better enhanced to promote their mainstream ideology and enhance the college students' longing for the Communist Party and further enhance the role of ideological and political work in the cultivation of higher vocational students. Higher vocational colleges should implement the concept of sustainable development, realize the innovation of community management and actively explore the use of new media and other means to innovate and improve the form of community management.

\subsection{The effectiveness of class attendance needs to be strengthened and the timeliness of class attendance needs to be improved.}

The classes in higher vocational colleges are based on the class, as well as the classroom attendance. The data of class attendance is conducted from the three lines at the same time. There may be discrepancies in attendance data. At this time, three lines are required to verify the accuracy of the data and submit an accurate data for management. The machine for attendance requires the card operation in machine. Some students may not come to class. We must make full use of the advantage of "Internet Plus", brushing fingerprints instead of swiping cards to improve the effectiveness of class attendance. The students in the same dormitory cannot help the others swiping cards in the context of "Internet Plus". The teachers' may have too many classes. They cannot remember every student's name and appearance. We can use the advantage of "Internet Plus" and sign online in class and upload the students' own photos on the homepage of the sign-in. Class discipline inspection committee attendance is the students' attendance. It is necessary to strict the requirements for student cadres that the student cadres must be required to be fair and selfless.

\subsection{The forms and contents of management in higher vocational colleges must be diversified to meet the characteristics of higher vocational colleges.}

The safety and stability workers in vocational colleges should establish a WeChat public account and Sina microblog account. By using WeChat, they can daily publish relevant safety and stability related articles for students, strengthen their ideological and political education and daily safety education on campus. By using Sina microblog, they can interact with the students, for example, it publishes systems related to campus security and stability. In these ways, the students can maintain their ideological education at any time. The students can also learn about the school's community return, classroom management and campus security and some other related systems. 
The security and stability of higher vocational colleges can be reformed by changing the linkage of several or all of the five aspects, that is, students, teachers, dormitory administrators, schools and parents. While combining the professional quality of students with the safety and stability of campus work, we can increase the campus safety and stability work forms, provide more theoretical references for the school and improve the students' professional quality and safety and stability. For certain sense, these can make up the current campus safety and stability work which is not perfect and the high-cost in campus security and stability. Thus, it will be more in line with the development characteristics of higher vocational colleges [6].

\section{References}

[1] T. Y. Bai, L. T. Chen, X. G. Zhang. A Preliminary Study of College Students' Network Security Education in the Background of "Internet Plus" and Big Data [J]. Journal of Hebei North University (Social Sciences Edition), 2016, 5.

[2] C. F. Wan, J. X. Xia. Analysis of the Urgency of Strengthening College Students' Safety Education [J]. Science \& Technology Information, 2015, 8.

[3] Y. Zhao. The Influencing Factors and Countermeasures of College Students' Safety Problems [J]. Education and Vocation, 2014, 20. 